\title{
Reescritura y tensión utópica en Noticias de extranjero (1959-1998) de Pedro Lastra
}

\author{
JuAn José D ANeri
}

East C arolina University, N orth C arolina, USA

E-mail: danerij@mail.ecu.edu

\section{Resumen}

Este artículo constituye el trabajo más reciente sobre la escritura poética del poeta y ensayista Pedro Lastra, materializada en la última edición de su libro $\mathrm{N}$ oticiasdel extranje ro. Así, sobre la base de la escritura crítica ya existente sobre su poesía y de conceptos específicos del discurso filosófico y teórico-literario contemporáneos, se la describe en términos generales y se la analiza en fragmentos específicos, profundizando en características ya detectadas por la crítica precedente y aportando una nueva mirada, la que destaca la dimensión utópica de la sugerente poesía del poeta chileno.

Palabras claves: Poesía, identidad, utopía, extranjero, viaje, escritura, reescritura, intertextualidad, lectura, sueño.

\section{Abstract}

This article constitutes the most recent work about poetical writing by the poet and essayist Pedro Lastra. All this is shown in the last edition of his book Noticias del extranjero. Thus, based on existent critical writing about his poetry, and specific concepts of contemporary philosophical and theoretical-literary discourse, the book is analyzed in broad terms and in specific fragments, deepening in characteristics al ready detected by previous criticism, and also giving a new review, which highlights the utopian dimension from the suggestive poetry of this $C$ hilean poet.

Keywords: Poetry, Identity, utopia, foreigner, travel, writing, rewriting, intertextuality, reading, dream.

Recibido: 13-06-2005. Aceptado: 16-07-2005.

- N CONTRARSE con la obra poética de Pedro Lastra es tener enfrente un

- cuerpo de textos que se han escrito, desescrito y reescrito en un periodo de 
unos cuarenta años. Se trata en verdad de un solo libro que al pasar de edición en edición pone de manifiesto una singular escritura poética y un proceso de lectura que genera su reescritura. Este trabajo estudia la relación entre estas características de la obra de Lastra y la persistencia de elementos utópicos en el lenguaje y las imágenes en N oticias del extranjero (1959-1998), laúltima reescritura del poeta chileno publicada en 19981. M i objetivo es demostrar que la poética de Lastra tiene elementos de la tradición utópica y que la aproximación más adecuada a estas manifestaciones textual es es desde el pensamiento utópico heterodoxo. M i análisis pone especial atención en el tema del viaje, la intertextualidad y la figura del extranjero, como el elemento que aglutina las tensiones utópicas en esta obra.

La palabra 'extranjero' en la poesía de Lastra, como ha señalado Francisco Rivera, se refiere no sólo a una persona que no es propia del país sino también al espacio que se encuentra más allá de la frontera ("H acia una lectura de N oticias del extranjero", 836). Esta definición privilegia una lectura desde los principios del Estado-nación y por tanto no contempla necesariamente condiciones de subalternidad dentro del Estado basadas, por ejemplo, en etnicidad o género. M i intención no es echar por tierra la aproximación de Rivera sino más bien abrir la noción de 'extranjero' al campo cultural y social, para dar cuenta de la complejidad de estas $\mathrm{N}$ oticias de 1998. Para esto, me gustaría trabajar con una definición operativa un poco más amplia. En su artículo "H ome and I dentity", $M$ adan Sarup se pregunta quién es un extranjero ("foreigner") y explica: "The one who does not belong to the group, who is not 'one of them'" (99). Y seguidamente cita a Julia K risteva:

The foreigner is the other of the family, the clan, the tribe. At first, he blends with the enemy. External to my religion, too, he could have been the heathen, the heretic. N ot having made an oath of fealty to my lord, he was born on another land, foreign to the kingdom or the empire (Strangers to Ourselves, 95).

Como se aprecia en ambas definiciones, la persona extranjera se define más por negación. Es lo que no somos. Esta imprecisión se relaciona con aspectos esencial es en la poesía de Lastra. En la bibliografía sobre su obra se puede distinguir dos tipos de textos: los análisis críticos y las variadas entrevistas. Junto con ofrecer una cantidad de información y de ideas útiles para el trabajo analítico,

\footnotetext{
${ }^{1}$ Noticias del extranjero tiene hasta el momento cuatro ediciones, 1979, 1982, 1992 y 1998. Para una caracterización de las operaciones básicas que organizan esta reescritura en sus tres primeras ediciones, ver M iguel Gomes, "Sueños de paraíso y de luz", 105-108. Todas las citas y referenciasfueron tomadas de la edición de 1998, que en el texto aparececomo $\mathrm{N}$ oticias.
} 
destaca una característica común en dichas entrevistas: en la mayoría de los casos, se trata de entrevistadores que comparten una amistad y un oficio con el poeta 2 . Se trata de otros poetas que son críticos, editores y académicos como el autor y que entran en una "convivencia dialógica" que ha generado no sólo entrevistas sino también un libro que sigue dicho formato Conversaciones con Enrique Lihn de $1980^{3}$. Resalta un contraste de tono entre la familiaridad de las entrevistas y la extrañeza que la crítica ha encontrado en su poesía ${ }^{4}$. La riqueza y la complejidad de la obra de Lastra están en buena parte en esa oscilación entre lo conocido y lo desconocido. M ás aún, esta poesía pone en movimiento una búsqueda que encuentra y genera imágenes imprecisas de su objeto del deseo ${ }^{5}$. En "Espero cada día que cantela sirena", el hablante, un 0 diseo moderno, afirma "no pienso taparme con cera los oídos" y dice que seguirá el canto de la sirena hacia la orilla. A parte el juego intertextual con poemas como "I taca" de Kavafis y la relación dinámica que establece entre fuentes, el texto señala:

\author{
bogaré hacia la orilla \\ sorteando las aguas resonantes, \\ las agitadas olas que dibujan tu rostro (N oticias, 47).
}

El rostro del último verso no es una imagen estática sino en constantemovimiento por $\mathrm{el}$ ir y venir de las olas. Los poemas de $\mathrm{N}$ oticias presentan una imagen de la amada lejana, parcialmente definida o simplemente contradictoria:

${ }^{2}$ M ario Rojas, "Entrevista con Pedro Lastra", D iscurso literario 2.2 (1985): 379-394. Enrique Lihn, "Las luengas peregrinaciones, ihacen a los hombres discretos?", Pedro Lastra 0 la erudición compartida, M.A. Rojas \& R. H ozven, eds., Puebla: Premiá, 1988. 63-68. M iguel Angel Zapata, “Pedro Lastra: La restricción de la palabra", Inti 26-27 (1988): 197-205. Edgar 0 'H ara, "La poesía es el pez en el agua: Conversación con Pedro Lastra", Inti 43-44 (1996): 343-359; “El poema: C aballero inexistente”, La precaución y la vigilancia, 73-132. Luis R ebaza Soraluz, "Pedro Lastra y la pasión americanista: Uno de los nuestros en Long Island", Atenea 474 (1996): 185-199. Arturo Gutiérrez P., "En diálogo con Pedro Lastra”, A tenea 480 (1999): 181-191.

${ }^{3}$ El término "convivencia dialógica" está tomado de la introducción, donde Lastra y Lihn explican su método de trabajo (Conversaciones, 9)

${ }^{4}$ Recientemente, el poeta se ha referido al extrañamiento y desconcierto ante el vivir mismo y comenta que "la noción de extranjería materializa verbalmente esa perplejidad" (Cruz, "Lector de todas las horas. Entrevista a Pedro Lastra", 3-5). Le agradezco a Pedro Lastra haberme facilitado una copia de esta entrevista inédita.

${ }^{5}$ M.A. Zapata afirma que N oticias "traza una poética en movimiento" que relaciona lenguaje y experiencia vivida (real o ficticia). Identifica además un peregrinaje interior y otro exterior: interior en el nivel subconsciente y exterior hacia lugares reales 0 imaginarios ("M orada y memoria de Pedro Lastra", 296). 
Cómo será, señora, verte y no verte

más, cómo será

mirar tu neblinosa

figura que se aleja

(esto lo escribo apenas),

porque estamos en mundos distintos.

("C asi letanía". N oticias, 53).

Esta representación de la amada está relacionada con un tema mayor que es el de la indefinición de imágenes del deseo en general, de "figuras entrevistas y sentidas por un durmiente" ("Carta nocturna”, N oticias, 59). Las imágenes vislumbradas en sueños o durante la vigilia remiten a una tensión utópica de búsqueda que no alcanza el objeto del deseo, el cual puede ser un lugar, un sentimiento, una persona ajena, como en "Fascinación del vacío", o aquello de lo que carece el hablante, como en "C asi letanía", poema al que volveré más abajo (N oticias, 56; 53).

Aunque lo familiar y lo desconocido han sido estudiados en la obra de Lastra, por lo general se ha hecho una lectura estática de su poesía, en el sentido de que se asume la condición de extranjero más como estado que como proceso ${ }^{6}$. Por otro lado, en una entrevista el poeta quizás sin intención parece legitimar dicho presupuesto al identificar la poesía con la representación en tanto reflejo de la realidad ("Poesía y exilio", 104; 109; 111). Aunque mi propósito no es etiquetar esta poesía, me interesa considerar lo que la crítica ha consignado y afinar aquellos aspectos que parecen relevantes. En mi lectura el extranjero es aquella persona que cruza una frontera, es decir, que se desplaza física y culturalmente y que, por tanto, está identificada con el movimiento. M ás adelante se verá que la práctica escritural de Lastra rebasa los límites dela representación. EI asunto a consideración, en este punto, es el del movimiento, el que guarda una relación directa con el concepto de identidad. Sarup define esta última como "[...] a construction, a consequence of a process of interaction between people, institutions and practices". M ás aún, el filósofo afirma quela identidad no tiene que ver con 'ser' sino con 'llegar a ser' ("H ome and Identity", 102; 98).

La obra de Lastra presenta tanto al sujeto como al objeto en esta dinámica del llegar a ser. A rriba hice referencia a la identidad del objeto del deseo (conocido/desconocido, definido/indefinido). En cuanto a la relación entre el sujeto

${ }^{6}$ En ocasiones esto podría ser producto dela influencia más o menos explícita de la biografía del poeta en el análisis. Ver, por ejemplo, D omínguez Vial, "Pedro Lastra ha vivido gran parte de su vida en el extranjero. Por eso dice: El desterrado busca [...]" ("La poesía de Pedro Lastra", 220). Sobre este tema y la recepción de la obra de Lastra, consultar O 'H ara, La precaución y la vigilancia, 51-52. 
y su mundo, el poema "Carta nocturna" conecta el objeto del deseo con la circunstancia objetiva o intersubjetiva: "tú serías mi principio de realidad" (N oticias, 59). Sin entrar en una discusión psicoanalítica, sólo quiero anotar que el objeto del deseo no toma el lugar de la realidad sino que define cómo el sujeto se relaciona con el mundo. En cuanto a la identidad misma del sujeto, el hablante se pregunta "quién buscará la otra parte de mí" en "Carta nocturna" ( $N$ oticias, 53). En todo caso, se trata de un sujeto para quien "N o sirve la fijeza" ( $N$ oticias, 84 ) y es en parte heterónomo, es decir, sometido parcialmente a la ley de otro.

La identidad en vilo del sujeto de la enunciación en la obra de Pedro Lastra se puede considerar tanto síntoma de una carencia más o menos explícita como condicionante de una búsqueda. Antes de entrar en el tema de hacia dónde se encamina esta búsqueda, me gustaría conectar esta exploración con un concepto de utopía que reflejela dinámica que presenta esta poesía. La literatura llamada utópica se identifica tradicionalmente con obras literarias que representan un mundo alternativo. Tanto en esta vertiente como en la de su opuesto, la antiutopía, se trata de textos dominados en la mayoría de los casos por la descripción. M ás aún, los personajes son planos, carecen de psicología y la acción está definida por la rutina. Son representaciones sincrónicas en donde un presente continuo desarraiga la acción del pasado y el futuro. En más de un sentido, se trata de un "tiempo vertical"7. Un gran crítico de la utopía, E.M . Cioran, sostiene que, a pesar de que la literatura utópica es un género aborrecible - aparte de Swift quien con sus sarcasmos logró, según él, "a déniaisé un genre au point de I'anéantir" (H istoire et utopie, 142)- tiene una función social importante. Supongamos, plantea Cioran, que nos dejamos de especulaciones utópicas acerca de un mundo mejor e ideal, ¿qué sucedería?:

[...] une stagnation totale s'ensuivrait. N ous n'agissons que sous la fascination de l'impossible: autant dire qu'une société incapable d'enfanter una utopie et des'y vouer est menacée de sclérose et de ruine (H istoire et utopie, 138-139).

Aunque para el filósofo de La tentation d'exister las únicas utopías legibles son las falsas (H istoire et utopie, 142), la rescata como agente de cambio. Es en este aspecto que resulta adecuado subrayar el sentido y la fuerza de la utopía, más que en las imágenes desiderativas o representaciones visuales del no-lugar.

\footnotetext{
${ }^{7}$ Estoy empleando una expresión de G astón Bachelard cuando explica queel poema verdadero debe producir un instante fuera de la continuidad del tiempo (Le droit de rêver. París: Presses U niversitai res de France, 1970. 224-225). Como se verá a continuación, la poética de Lastra no sigue esta ontología que propone Bachelard.
} 
Y en el caso específico de Lastra, la imposibilidad de formular imágenes que califiquen como utópicas es un tema que aparece en textos claves, como en "Peligro", en donde está la presencia de dos elementos de esta natural eza que luego son descalificados por un adversativo:

Caminabas

en dirección contraria del otoño

bajo los grandes árboles y luego era la costa (una isla sin duda)

$[\ldots]$

pero algo andaba mal en el paisaje ( $\mathrm{N}$ oticias, 40).

El movimiento en sentido opuesto al del otoño, es decir, de vuelta hacia el verano, y la mención a la isla donde "el sol ahora con los hombres / y mujeres felices" pertenecen a la tradición literaria utópica. Sin embargo, este paisaje 0 visión no funciona bien, y el texto no ofrece más detalles al respecto. H ay aquí un movimiento que se inicia al principio del poema donde un "tú" se desplaza en el pretérito a través de un paisaje que se verifica imperfecto en el octavo verso. El pretérito imperfecto que domina el texto pone demanifiesto un movimiento que se desarrolla en el pasado y que tiene como telón de fondo un paisaje que se pierde junto con el sujeto del enunciad $0^{8}$.

Concebir la utopía más bien como un mecanismo pone de manifiesto el aspecto dinámico del concepto. En este contexto y en este sentido la obra poé tica de L astra posee rasgos utópicos 0, mejor dicho, tensiones de carácter utópico. Antes de entrar en esto, es necesario refinar un poco más esta aproximación teórica y me gustaría traer a colación la conceptualización que Ernst Bloch ha elaborado acerca de la función utópica y la pre-apariencia estética. En su obra D asPrinzip H offnung, Bloch explica que el arte tiene una función anticipatoria porque es una especie de laboratorio generador de posibilidades (D as Prinzip $\mathrm{H}$ offnung, I 209). Las imágenes que presenta el arte entonces son una pre-apariencia ("Vor-Schein") de algo que todavía no es pero que puede llegar a ser. Bloch identifica una función ("utopische Funktion") que genera el proceso de configuración estética y queestá presente en ese fragmento quees la obra dearte (D as Prinzip H offnung, I 214-215) ${ }^{9}$. Se trata de fragmentos porque el arte no

\footnotetext{
${ }^{8}$ El último verso del poema insiste en el carácter pasado de las imágenes al introducir e pretérito perfecto con un verso del soneto XXXVII de Fernando de H errera: "passó, cual rota niebla por el viento". Este cancela la proposición utópica pero a la vez lanza al lector en busca del intertexto.

${ }^{9}$ Para un análisis comprensivo de su obra, ver Richard $\mathrm{H}$. Roberts, $\mathrm{H}$ ope and I ts H ieroglyph. A Critical D ecipherment of Ernst Bloch's Principle of H ope (Atlanta: Scholars Press, 1990), esp. 27-48.
} 
puedegenerar totalidades quereemplacen el mundo real, sin embargo, son imágenes del deseo que presentan momentos plenos desconocidos antes de la configuración estética (D as Prinzip H offnung, III 7). Es decir, el arte constituye un acto cognitivo porque es vía de conocimiento de aquello que todavía no es ("N och-N icht-Sein"). A Bloch le interesan sobremanera personajes literarios como don Q uijote, don Juan o Fausto porque, especialmente este último, representan figuras que intentan cruzar un límite o una frontera. Para Bloch se trata de la invención de un mundo auténtico caracterizado por la vuelta a la "patria" en la que nunca se ha habitado (D as Prinzip H offnung, III 501).

Aunque mi intención no es sugerir que la obra de Lastra satisface todos y cada uno de los aspectos mencionados por Bloch, me gustaría proponer esta conceptualización como punto de partida para comprender mejor la poética queha estado en juego en y queen última instancia genera las diferentes ediciones de las $\mathrm{N}$ oticias del extranjero ${ }^{10}$. El poema que mejor muestra la presencia de una tensión utópica es "Carta de navegación", en donde aparecen dos temas importantes, el viaje y el porvenir:

El futuro está claro

pero el presente es imprevisible (N oticias, 32).

La categoría de futuro es la que, según Bloch, defineal impulso utópico pues es allí en donde existe la posibilidad de que se resuelva la carencia presente. Esto aparece en el primer verso, sin embargo, la claridad del futuro no está calificada por ninguna imagen del deseo; se podría decir que es el deseo puro, sin referente. El adversativo que inicia el segundo verso no sólo introduce el carácter imprevisto del presente sino que implica que dicho carácter afecta de alguna manera a esa claridad del futuro. El poema presenta una paradoja porque si el presente es imprevisible, entonces la aseveración del primer verso, cuya enunciación ocurre en el presente, se vuelve en parte inestable. Si bien la inestabilidad se puede leer como un rasgo negativo, el título del poema considera dicha vacilación como prueba de que se está en marcha. Este poema enfatiza por tanto el movimiento hacia el futuro, dejando ese futuro incierto. D e manera similar, para Bloch, la esperanza no es sinónimo de confianza. En su diálogo de 1964 con Theodor W. Adorno, señala:

${ }^{10}$ En la literatura sobre la obra de Lastra hay escasas referencias al tema utópico (o antiutópico) y se trata en general de comentarios aislados. Ver M aría N ieves Alonso, "B lues del extranjero", 124, y Carmen Foxley, "Intervención al margen", 101. M artha Canfield, por otro lado, ha identificado el sueño como territorio utópico accesible en el nivel del contenido, y relaciona este tema con el exilio ("Eternità dell'esilio", 31-33). M i lectura trabaja con una noción diferente de utopía y, como se verá, va más allá del ámbito del contenido. 
H ope is not confidence. If it could not be disappointed, it would not behope. That is part of it. 0 therwise, it would be cast in a picture. It would let itself be bargained down. It would capitulate and say, that is what I had hoped for. Thus, hope is critical and can be disappointed [... ] H ope is surrounded by dangers, and it is the consciousness of danger and at the same time the determined negation of that which continually makes the opposite of the hopedfor object possible ("Something's M issing", 16-17).

El poema de Lastra y su poesía en conjunto no reflejan una negación de ese peligro del que habla Bloch sino más bien una consignación de su existencia, la cual se manifiesta en la forma en que se articulan las imágenes del deseo. Aún así, persiste una tensión entre sujeto y objeto. Para comprender mejor la forma en que aparece este último dentro de coordenadas utópicas, es necesario considerar el poema "Paraísos" que sirve de entrada al tema de la modulación de las imágenes utópicas en esta poesía:

\author{
El niño que construye \\ en el mundo visible \\ su pequeño paraíso \\ velozmente \\ se adelanta a los días \\ e instala en su memoria \\ el paraíso perdido (N oticias, 68).
}

El plural del título insinúa un cambio en cuanto a las utopías tradicionales: no se trata ya de una visión totalizante sino de una multiplicidad, de la cual la que presenta este poema es una de sus posibilidades. La primera estrofa, por otro lado, separa el texto de las utopías heterónomas como la del Jardín del Edén porque es un paraíso "pequeño" construido por un humano. No hay aquí divinidades ni seres superiores; se está en el mundo humano del trabajo"1. El "pequeño paraíso" es una pre-aparición pero al mismo tiempo es recuerdo, es decir, está antes y después del presente de su producción, y además se encuentra perdido. Al parecer, este ideal restringido es por definición imposible. El adverbio que constituye la segunda estrofa se refiere tanto al proceso de elaboración como al de instalación en la memoria y su consecuente pérdida. El poema construye un dilema, "una postergación infinita que es también recuperación de lo perdido"

\footnotetext{
${ }^{11} \mathrm{El}$ tema de un paraíso de factura humana se encuentra también en "El exilio o el reino", en donde se implica además que ha habido al menos una expulsión anterior pero quetambién fue de un paráíso creado por humanos: "Si algún dios furibundo / nos expulsa otra vez del paraíso / que tú y yo hemos creado / fundaremos una nueva ciudad [...]" (N oticias, 49).
} 
(Gomes, "Sueños de paraíso y de luz", 112). U na disyuntiva más que contribuye a enfatizar las oscilaciones: el agente de los dos primeros versos del último terceto puede ser 'niño' o 'paraíso'.

En el marco conceptual deBloch, el arte presenta imágenes que constituyen preapariciones. En la poesía de Lastra, sin embargo, aquellas representaciones quesepodrían considerar "Vor-Schein" están incompletas, son inestables o simplemente no tienen una presencia textual y sólo se encuentra una referencia a ellas ${ }^{12}$. Estees el caso del "pequeño paraíso" en el texto anterior, en donde existe la referencia al paraíso, ya sea su versión individual ("su pequeño paraíso") 0 quizás colectiva ("el paraíso perdido"), pero el poema no expone una imagen de ninguno de los dos. Algo semejante sucede en "Variaciones sobre un tema de D uchamp", donde el hablante tieneen el sueño la experiencia física de la "certeza absoluta" y a la vez "inalcanzable" del objeto del deseo (N oticias, 81). El objeto está en proceso de transformación y a la vez se encuentra diferido: el sujeto lo escucha, lo mira, pero no se manifiesta textualmente. El adjetivo "rumoroso" quecalifica al objeto se refiere así a un producto o efecto del objeto, pero no a su productor o causa.

El poema "Informe para extranjeros" (N oticias, 29) presenta imágenes casi fotográficas o pictóricas de espacios domésticos que se podrían relacionar con la biografía del autor ${ }^{13}$. A pesar de que dichas representaciones son familiares, su configuración como grupo de visual izaciones es más bien fragmentaria. D ehe cho, lasimágenes del padre, lasflores y la primavera al final de la primera estrofa parecieran localizarseen diferentes lugares simultáneamente: "séquees en C hillán, I sla N egra, Santiago". Esto explica asimismo el tiempo presente de los verbos y lo relaciona además con representaciones típicamente oníricas. El tercer verso desfamiliariza la relación al instalar una distancia entre estas representaciones y el hablante: "mis hermanos me miran y no me reconocen". La última estrofa de un solo verso se caracteriza por una declaración lanzada al futuro ya sea como deseo, mandato o sugerencia: "Q ue no haya tristeza". Aisladamente, este verso cabe dentro de los deseos típicamente utópicos en tanto esperanza de eliminar la tristeza. Sin embargo, en el contexto del poema sugiere resignación o contentamiento: a pesar de la fragmentación y la disociación, no debe haber tristeza. Esto es lo que el hablante intenta comunicarles a los extranjeros en su informe.

\footnotetext{
${ }^{12} \mathrm{El}$ uso de décticos funciona de este modo. Ver, por ejemplo, "Allí se mira y se recuerda a veces", en el cual el déctico del título y del tercer verso se refieren a un lugar en donde ha habido una pérdida de al go que no está definido ( $N$ oticias, 80 ). Lastra explica que los dé́cticos "no pueden remitir a una presencia sino a una ausencia" en el caso de lo que llama "poesía exiliar" ("Poesía y exilio", 106).

${ }^{13}$ Sobre la relación entre Lastra y la pintura, ver La precaución y la vigilancia, 86-93.
} 
Lo que destaca en la poesía de Lastra no son sólo las pre-apariciones que se manifiestan en el nivel del contenido sino también el modo en que están articuladas 0 se hace referencia a ellas. Para considerar la forma en que las imprecisas imágenes del objeto del deseo aparecen en los poemas hay que indagar en el lenguaje. El primer verso del poema "Por los poetas perdidos" da una clave sobre este tema: "N osotros disputamos a otro reino sus nombres" (N oticias, 90). La querella entre este "nosotros" colectivo y el "otro reino" es acerca de "nombres", es decir, palabras o más precisamente sustantivos. Estees el ámbito donde sejuega la poética de Lastra, el de la expresión. La preocupación por el lenguaje mismo es una característica de la poesía en general y en particular de las poéticas desde los inicios de la modernidad artística. En el caso de la obra de Lastra es especialmente relevante por su reescritura constante y persistente intertextualidad.

El fenómeno de la reescritura en la obra de Pedro Lastra, una de las características más sobresalientes de su poesía, ha sido considerado por la crítica como una búsqueda de exactitud en la expresión ${ }^{14}$. La reescritura en este cuerpo de textos no es sólo una práctica que tiene como objetivo la precisión, sino también un fenómeno relacionado estrechamente con la lectura, la relectura y la intertextualidad. En este sentido, la reescritura como fenómeno en Lastra se asemeja a la noción de "patria" a la que se refería Bloch. Para esteúltimo, el arte anticipa un mundo auténtico que constituye la patria o el hogar todavía no habitado. A propósito del poema "El exilio o el reino", M artha Canfield afirma que "la scrittura [... ] acquista forma il sogno del paradiso ritrovato" ("Eternità dell'esilio", 35). Pero más allá de configuraciones utópicas, la pregunta que hay que hacerse acerca de la obra de Lastra como fenómeno poético es: ¿Adónde vuelve esta poesía una y otra vez? Pues, a sí misma. M ás aún, vuelve una y otra vez para reescribirse. D e manera que si la reescritura en esta poesía no es sólo práctica sino fenómeno, dicho fenómeno adopta la forma de un retorno a un lugar específico, el texto, y con una función más o menos obvia, la de la corrección. Si en coordenadas del pensamiento utópico de Bloch se desea volver a la patria 0 al hogar, es posible postular queel lugar que posee una función equivalente a la de la patria o el hogar en la poesía de Lastra es el poema. M ás específicamente sus propios poemas, y los textos de los otros poetas con cuyas obras se establecen relaciones de intertextualidad ${ }^{15}$. En las páginas que quedan indicaré las características de este "hogar poético" al queel poeta vuelve sistemáticamente, desde su primera publicación en 1959 hasta la última entrega de 1998.

\footnotetext{
${ }^{14}$ Zapata, "M orada y memoria de Pedro Lastra”, 295. O 'H ara, La vigilancia y la precaución, 16.

${ }^{15}$ Lastra señala: "La patria de un poeta es la poesía” (Rojas, "Entrevista con Pedro Lastra”,
} 
El tema del viaje recorre toda la obra de Pedro Lastra y define uno de los motivos más constantes en su producción literaria. Se manifiesta delas maneras más tradicionales, como en "Línea de flotación", donde el personaje masculino seencuentraliteral y existencialmentea la deriva: "Lejos detodo, ¿quién? / ¿El que miraba / o el que era visto? / Eso no lo sabe [...]" (N oticias, 76). En un lenguaje que recuerda a Borges 0 C ortázar, el texto estableceuna relación directa entreviaje e identidad al modo de los relatos canónicos de autores como J oseph Conrad, en donde ocurre un viaje interno paralelo al desplazamiento físico. En general, se trata de una experiencia individual ("se viaja solo") caracterizada por cierta nostalgia de heroicidad, como en los poemas que recuerdan a descubridores y conquistadores españoles del siglo XVI (N oticias, 80; 88; 89). D icha añoranza está conectada asimismo con la búsqueda de oro y de espacios utópicos. En el caso de "Primavera extraviada", el hablantesientenostalgia de un cierto tipo de árbol quePigafetta encontró en Borneo cuyas hojas "vivían del aire" y tenían "sus dos pies" (N oticias, 89). Estas hojas "al caer se animaban" y una de ellas se paseó a su al rededor al sacarla de la caja en que el navegante la había guardado. La imagen de la hoja animada amplía el campo de referencia más allá de lo utópico al incorporar la hoja como instrumento de la escritura ("Anotó que se escapaban al tocarlas [...]"). El viaje se relaciona entonces con la escritura.

Viaje y escritura aparecen vinculados en "Comunicado de González Vera: los planes dela noche", donde se sugiere que "el puro viaje" es escribir (N oticias, 28). Pero se trata de al go no total mente positivo porque es lo único que queda por hacer, incluso la vida misma ha desaparecido"16. El poema "Fascinación del vacío" también presenta la escritura como última opción, cuyo tema es la historia de un viaje que un "tú" no ha realizado. En este texto, el hablante está buscando a esa persona en una carretera. El viaje del hablante es por tanto el acto de escritura del poema. Y la escritura en la obra de L astra es un tema inseparable de la lectura, ya que ambos configuran el fenómeno de la intertextualidad.

La lectura es un recorrido textual que ineludiblemente implica un abandono: parafraseando a Cortázar, el sujeto lector debe desgajarse línea a línea de aquello que lo rodea y dejarse ir hacia las imágenes que presenta el texto ${ }^{17}$. D e ahí que el hablante se embarque en una "palabrera piragua": él produce el poema pero a la vez es llevado por su propio texto ( $N$ oticias, 71). I r hacia un texto 0 dejarse llevar por él en la obra de Lastra remite a uno de los temas más impor-

${ }^{16}$ Como coloquialismo chileno, la sintaxis de la proposición "el puro viaje" implica queel viaje es la única actividad posible ("puro viaje"="sólo el viaje").

17 "Continuidad de los parques" (Final del juego, Buenos Aires: Sudamericana/Planeta, 1990. 9) 
tantes en su poética: la intertextualidad ${ }^{18}$. N oticias es un libro que tras sus continuas revisiones ha sido despejado de referencias bibliográficas en la forma de notas a pie de página. En el texto antes mencionado sobre Pigafetta, por otro lado, se reproduce una sección de su Primo viaggio intorno al globo terracqueo (1536) mediante una paráfrasis. En un poema en el que el hablante enuncia un soliloquio, la vigilia, asociada con el día, está identificada con "[...] un largo diálogo / de palabras cruzadas", y la noche con el sueño, los fantasmas y por extensión con la escritura ("Instrucciones para la vigilia". N oticias, 77). El día se relaciona entonces con la lectura, en donde ese "diálogo de palabras cruzadas" está constituido por el ejercicio de la intertextualidad. El texto y el intertexto, por otra parte, son simultáneamente traslaciones de aquello de que se habla, como en "La otra versión", dondeel poema es una versión, de la cual la escritura "en sueños" es su alteridad. El texto sugiere además que escribir y soñar son operaciones equivalentes cuyo constante empeño no necesariamente acerca al sujeto a su objeto sino, muy por el contrario, lo disuelve: "tanto soñé contigo que pierdes tu realidad" (N oticias, 61) ${ }^{19}$. La lectura de libros está relacionada asimismo con dos actos que parecen intercambiables: leer y recordar ("La historia central", N oticias, 60). El poema donde más dramáticamente se manifiesta el fenómeno de la intertextualidad es "D iario de viaje":

N o tengo nada que encontrar en la realidad,

un paisaje agotado por los viajeros

que me han precedido en el ejercicio de estas contemplaciones

(N oticias, 22).

En la relación entre hablante y mundo, éste ha sido reemplazado por las "contemplaciones" de otros "viajeros" que le precedieron. El demostrativo en "estas contem placiones" en el último verso tiene una función deíctica que indica hacia el texto mismo. En la relación sujeto-objeto al hablante sólo le queda el producto del "ejercicio" propio y el ajeno, es decir, los poemas. En más de un sentido, el texto poético se ha vuelto el mundo. En consecuencia, el viaje es el ejercicio de la lectura.

La intertextualidad es el fenómeno que organiza la escritura de Lastra: se trata de un proceso escritural que incorpora textos ajenos y reescribe los pro-

\footnotetext{
${ }^{18}$ Sobreintertextualidad, ver Lucien D allenbach, TheM irror in theText (C hicago: Chicago University Press, 1989) y Graham Allen, Intertextuality (Londres: Routledge, 2000).

${ }^{19}$ Las cursivas en el original indican que el verso viene de un poema de Robert $D$ esnos. Uno de los efectos del fenómeno de la intertextualidad es desestabilizar los referentes, algo semejante a lo que postula el texto: la pérdida de realidad del objeto es efecto del persistente soñar del sujeto.
} 
pios $^{20}$. El poeta ha indicado además queen su labor críticala intertextualidad es un presupuesto de trabajo (Rojas, "Entrevista con Pedro Lastra", 386). Lectura y escritura convergen en la práctica de la reescritura, uno de los rasgos esenciales de esta poética. Como ya se ha indicado, la escritura misma está asociada con el tema del viaje. Al mismo tiempo, viaje y escritura también están asociados en una relación compleja. En el poema "C omunicado de G onzález Vera”, mencionado antes, aparecen intrínsecamente ligados de un modo especial21. "Línea de flotación", por otra parte, acaba con referencias a la repetición:

O tra vez, otra vez

lejos de todo.

Las aguas, las espías, se apresuran a girar y girar sobre sí mismas (N oticias, 76).

N o sólo hay aquí reiteración, sino que la repetición misma está duplicada. La reincidencia es un acto que tiene un referente más o menos claro:

\author{
Vuelvo sobre lo mismo, pienso con gran cuidado \\ en lo que no nos pasa todavía, \\ preparo tus recuerdos y los míos \\ antes de que la memoria los juegue con cartas marcadas
}

("Para el coraje de vivir", N oticias, 67)

Aquello a lo que se vuelve es lo que aún no ha sucedido, es decir, la posibilidad. Y esos recuerdos del futuro emergen textualmente como imágenes del deseo que esta poesía pone delante del lector. Todo esto tiene relación con el tema del sexto sentido, que aparece en dos poemas de N oticias, "El sexto sentido" y "La penumbra es el sexto sentido" (37; 86). En este último, la escritura es el tema de fondo:

Y la penumbra como allá. La araña

que afina el tacto al recorrer el muro

\footnotetext{
${ }^{20} \mathrm{G}$ omes ha identificado el aspecto metaliterario: "Para el desterrado que se dibuja poema a poema [...] parece que lo único firme y definido que puede actuar como asidero es la escritura, la lectura" ("Sueños de paraíso y de luz", 110).

21 "'Se dispersó la vida, el puro viaje / es lo que va quedando? / ¿D e quévoy a escribir, qué puedo hacer ahora? / Y alguien borrosamente melo dice en el sueño: / 'Escribirás de los lugares" (Noticias, 28). H ay que notar que "lugares" se puede entender como referencia a textos citados. Aparte del hecho de que el hablante se encuentra en un cuarto vacío sin contacto directo con el exterior, el adverbio "borrosamente" no hace sino recalcar la identificación con la lectura.
} 


\section{me enseña a entretener aquí la espera mientras recuerdo o escribo en la penumbra a la espectral araña pasajera.}

D enuevo el hablanteestá caracterizado como al guien en espera y en proceso de recordar o escribir. El texto construye una serie de oposiciones: allá/aquí; hablante/araña; muro/página. Araña y poeta tejen en un espacio iluminado a medias, y la otra araña (hablante-escritura), fantasmagórica y efímera, no lle $\mathrm{ga}^{22}$. El ambiente interesa sobremanera porque este espacio se ubica entre los dos mundos que aparecen consistentemente en la obra de Lastra, la noche y el día, el sueño y la vigilia. La zona que articula estos dos ámbitos es también la de "D uermevela", texto que a su vez reitera su asociación con el lenguaje (N oticias, $85)^{23}$. Así como la zona intersticial dela penumbra es el sexto sentido, el poema del mismo nombre se refiere también a una dinámica específica:

Este día

y el otro

en mí tienen su origen y también su destino.

Si el sexto sentido es la penumbra que articula los dos mundos a través de la escritura, en "El sexto sentido" hay la presencia de una especie de alfa y omega: el origen y el destino del tiempo están en el hablante. El sujeto que enuncia es productor y producto de su propia actividad. Por lo tanto, el texto mismo es el principio y el fin de este sujeto. D e hecho, haciéndole una pequeña variante al título del poema es posibleconfirmar las actividades recursivas de leer y escribir: la similitud sonora entre "sexto" y "texto" Ilevan a definir "sexto sentido" como "texto sentido". El sentido del texto es el sexto sentido, el que hace falta para percibir esa otra realidad. Y como todo sentido, tienelímites, y desde este punto ciego es que se deduce la natural eza de las imágenes en los poemas de Lastra. Pero hay algo más: la palabra 'sentido' no sólo se refiere a un significado sino también a una dirección. ¿En qué dirección se encaminan entonces la escritura y la lectura en la poética de Lastra? En la de los textos que componen las $\mathrm{N}$ oti$\mathrm{cias}^{24}$. Y es exactamente esta actividad la que deviene reescritura. Esto explica

\footnotetext{
22 'Tejer' como metáfora de la escritura está presente también en "M ester de lejanía” (N oticias, 91).

${ }^{23}$ El poema presenta en su último verso una antítesis que contrasta una apariencia o forma bella con un contenido negativo: "paloma de la muerte". El texto sugiere asimismo la fragmentación de la memoria y su manifestación fraccionada en el lenguaje: "no es un nombre / son sílabas / idénticas a un nombre".

${ }^{24} \mathrm{M}$ arcelo Pellegrini habla de "una escritura de fijación intensa en la página” ("El ejercicio memorioso de Pedro Lastra", 355).
} 
que Pedro Lastra, en una entrevista con Edgar $\mathrm{O}$ 'H ara, haya señalado: "M i escritura poética sería una relectura de mis propios poemas..." ("La poesía es el pez en el agua", 357). Así, el tema del viaje deja de ser una metáfora o alegoría para convertirse en el acto mismo de la reescritura: el viaje es el trayecto no sólo desde el poema hacia el texto citado y de vuelta al punto de partida, en el caso de la intertextualidad, sino también desdeel poema original hacia su nueva versión ${ }^{25}$.

Como anoté antes, la crítica ha afirmado en varias ocasiones que el ejercicio de reescritura de Lastra es producto de una voluntad de precisión en la expresión. Este comentario describe una característica importante de su poesía en cuanto a la revisión de textos ya publicados ${ }^{26}$. Sin embargo, no explica una paradoja esencial relacionada con la otra paradoja, indicada al principio de este trabajo, entre la familiaridad de las entrevistas y la extrañeza de las imágenes en Ios poemas: ¿Para qué buscar casi obsesivamente la precisión de imágenes imprecisas? La respuesta a esta pregunta tiene que ver con el papel de la memoria en el proceso de escritura en la obra de Lastra.

La memoria tiene un rol clave porque está relacionada con todos los temas que organizan esta poesía: el viaje, la escritura, la lectura, la reescritura y el sueño. Está asociada, asimismo, con la tensión utópica en su doble aspecto temporal: no sólo es recuerdo de al go pasado sino que también es evocación de algo que no ha sucedido. Cito nuevamente "Para el coraje de vivir":

Vuelvo sobre lo mismo, pienso con gran cuidado

en lo que no nos pasa todavía,

preparo tus recuerdos y los míos

antes de que la memoria los juegue con cartas marcadas (N oticias, 67).

A partedelos elementos utópicostípicosy la obsesión expresada en el primer verso, se aprecia que la memoria trae al presente aquello que está atrás, pero también tiene un efecto negativo porque altera el recuerdo sin que el sujeto tenga control sobre dicha transformación. Esmemoria del pasado y también del

${ }^{25}$ Ver "Escorial" donde emerge la noción de palimpsesto (N oticias, 87). Por otro lado, $\mathrm{O}$ 'H ara identifica un caso de lo que llama "intertextualidad refleja" entre el poema "Espacios de Alvar N úñez" y el artículo crítico "Espacios de Alvar N úñez: Las transformaciones de una escritura" sobre el conquistador español publicado por Lastra en 1984 (La vigilancia y la pre caución, 57). La noción de "intertextualidad refleja" aparece en una entrevista de 1979 entre Lastra y Lihn (C onversaciones con Enrique Lihn, 141).

${ }^{26}$ Aunque en general los poemas revisados sufren un acortamiento, también es verdad que $\mathrm{N}$ oticias ha aumentado en número. Lastra ha dicho que su intención es ampliar este cuerpo de textos (La precaución y la vigilancia, 127), pero también explica que su temor al exceso o la gratuidad lo hace "reducir o eliminar gran parte de lo escrito" ("Pedro Lastra: La restricción de la palabra", 200). 
futuro, sin embargo, el hablante tiene la seguridad que no será igual. 0 será un imposible, como en el caso del paraíso perdido que se instala en la memoria como tal, perdido ("Paraísos"). El hecho que el recuerdo cambiey sea además fragmentario hace pensar en una suerte de neoplatonismo en la poesía de Lastra27. La persistencia del acto voluntario y sistemático de la reescritura es un intento de contrarrestar el proceso de disolución o cambio de la memoria sabien do que no es posible lograr este objetivo:

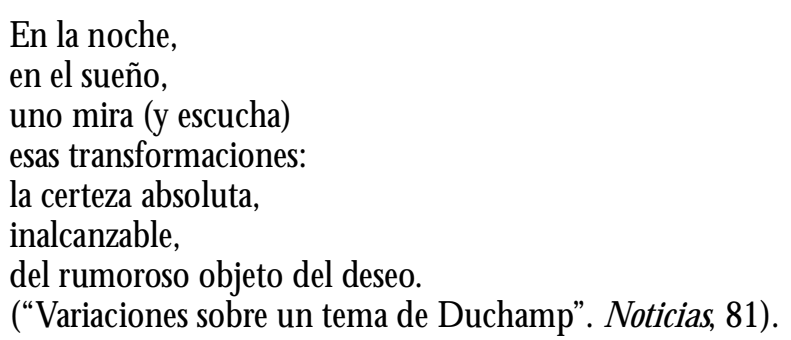

La estructura de este poema reproduce esa fragmentación que afecta el recuerdo y que se hace aparente en "D isolución de la memoria", en el quetema, imáge nes y organización llevan la marca de la separación: entre hablante y "tú", sueño y cielo, irrealidad y figura terrestre, memoria y silencio, tierra y agua (N oticias, 64). Esta poesía se reescribe entonces a pesar de la fragmentación y la separación, y de la certeza de la imposibilidad. Pero las imágenes que emergen caben en la categoría de fragmentos que se perciben por instantes, como en los poemas "Balada para una historia secreta", "Instantánea", "Aurora boreal" y "Aurora boreal (Variación)" (N oticias, 52; 63; 31; 65). La captura del instante es, de acuerdo con Bloch, la utopía de la existencia porque, al materializarse el objeto del deseo en el aquí y el ahora, se desea detener el tiempo, como Fausto de G oethe: " $i D$ etente, eres tan bello!" (D as Prinzip H offnung, III 106-107). Pero si la captura es improbable o no se manifiesta textualmente, para elaborar una respuesta más detallada a la pregunta sobre el sentido de la reescritura en la obra de Lastra, es necesario revisar el breve y revelador poema "Aurora boreal (Variación)".

${ }^{27} \mathrm{~L}$ a fragmentación de la memoria es un tema que aparece en poemas ya analizados como "D uermevela" y "Variaciones sobre un tema de Duchamp", el cual cito a continuación. El posible neoplatonismo seaprecia en el poema "El sol, autor de representaciones" (N oticias, 58). Sobre esta línea filosófica, consultar las Enéadas de Plotino especialmente en lo que respecta a su idea de que los tres tiempos, pasado, presente y futuro, son presentes (Ennéades. París: Les Belles Lettres, 1960. I, 5, 7). D icho presente absoluto, en la poesía de L astra, se condensaría en el fenómeno de la reescritura (lectura y escritura). 


\author{
El amor y la música \\ el silencio otra vez \\ y la memoria \\ del amor y la música (N oticias, 65).
}

Las dos estrofas están relacionadas en cuanto al contenido pero también se encuentran separadas por un silencio representado gráficamente en la página: la primera estrofa habla del amor y la música, y la segunda del recuerdo del amor y la música. La fugacidad del amor y la música parece compensarse con el re cuerdo que tiene de ellas el hablante. El hecho de que el poema sea una variación de otro poema prueba que la reescritura ha producido un texto más breve en el cual la memoria toma el lugar del objeto del deseo. Considerando la progresión que presenta el poema "Paraísos", en donde el pequeño paraíso individual del niño se transforma en laúltima estrofa en "el paraíso perdido" al formar parte del recuerdo, es posible postular que la memoria perfecciona el recuerdo $0^{28}$. Esto explica el motivo de la reescritura en la poesía de Lastra: a través del proceso de reescritura, la poética activa que organiza las N oticias no sólo intenta lograr mayor precisión sino quetambién vuelve a los textos anteriores porque ése es el lugar delos instantes preciados, las iluminaciones fugaces y los reencuentros. Por esto, en el poema "El desterrado busca” se lee:

\author{
El desterrado busca, \\ y en sueños reconoce su espacio más hermoso, \\ la casa de más aire ( $N$ oticias, 35).
}

Está claro que en la poesía de Lastra sueño y escritura constituyen dos caras de un mismo fenómeno. Al que habría que agregar la memoria. Se trata además de un espacio singular, el del hogar. La relación entre "desterrado" y "casa demás aire" recalca la significación del hogar para un expatriado ${ }^{29}$. La consecuencia lógica de que el poeta vuelva una y otra vez al texto para revisarlo y así cambiar el recuerdo es que su referente paulatinamente deja de ser el objeto del deseo, persona, lugar o circunstancia. El efecto de las continuas revisiones pone en

\footnotetext{
${ }_{28}^{28}$ Reproduzco nuevamente el poema: “El niño que construye / en el mundo visible / Su pequeño paraíso // velozmente // se adelanta a los días / e instala en su memoria / el paraíso perdido" (N oticias, 68).

${ }^{29} \mathrm{En}$ su artículo "Poesía y exilio" Lastra realiza un acto de intertextualidad refleja al citarse a sí mismo e incluir este poema como un caso de poesía exiliar. Q uiero destacar el aspecto anticipatorio que el crítico ve en su poema: "¿Por qué escribí esos versos? M ás de una vez he necesitado explicar que ellos no tuvieron su origen en el golpe militar y en sus funestas consecuencias. Pero ahí estaban, como una pequeña, misteriosa y sombría anticipación para mí mismo" (111).
} 
primer plano el hecho de que el referente más claro son las versiones anteriores de cada poema y también del cambiante cuerpo de textos que conforman las $\mathrm{N}$ oticias. Consecuentemente, el espacio del poema se transforma en el hogar que busca el extranjero. D e hecho, el poema "C ontracopla" sugiere, en su verso único, que el sueño, es decir, el poema, ha reemplazado a la realidad: "Regreso envejecido de los sueños" ( $\mathrm{N}$ oticias, 51 ) ${ }^{30}$. Esta poética proponepor tanto dejar en ocasiones la vida real por la vida verdadera, aunque ésta sea fragmentaria, contradictoria y efímera.

La figura del extranjero en tanto lugar e individuo en la obra de Pedro Lastra aglutina la serie de temas que convergen en el fenómeno y la práctica de la reescritura. La metódica recurrencia de la reescritura tiene el efecto de textualizar la experiencia radicalmente. La identificación entre la vida del hablante y los libros aparece en poemas como "N oticias del maestro Ricardo Latcham, muerto en La H abana", en donde el hablante se refiere a la biblioteca del crítico y a sus discípulos, entre los que se incluye el mismo Lastra:
Y nosotros, los encargados de conservarla para quienes llegaran después, nos dispersamos también como páginas arrancadas y rotas, lo que fue igual a desaparecer (N oticias, 108) ${ }^{31}$.

Por otro lado, el poeta ha declarado que "[I] a patria de un poeta es la poesía", confirmando tanto la textualización de la experiencia como la tensión utópica identificada en las páginas anteriore ${ }^{32}$. Representa asimismo esa ambigüedad quecaracteriza a esta poética: si bien la poesía es la patria del poeta, dicho hogar al que se vuelve una y otra vez sufre cambios sistemáticos como producto de las sucesivas reescrituras. La condición de extranjero se relaciona con una noción

${ }^{30}$ El poeta al hablar sobre la intertextualidad afirma que ésta "es mucho más vasta que la remisión deun texto a otro, más bien una deuna red infinita, lo cual nos lleva ineludiblemente a la conclusión de que todo es texto, a la amplia noción del 'mundo como texto'" (Rojas, "Entrevista con Pedro Lastra", 387). Lastra y Lihn se han referido asimismo a la relación entre intertextualidad y experiencia textualizada (C onversaciones con Enrique Lihn, 106-107). A propósito del poema "Copla" y el tema del exilio como estado permanente, M artha Canfield explica que el sueño sustituye a la vida en la obra de Lastra ("Eternità dell'esilio", 32).

${ }^{31}$ La biblioteca, uno de los temas más simbólicos de la textualización, aparece en textos como éste y en numerosas entrevistas al autor.

32 "U na experien cia literaria en su contexto" forma parte de la primera edición de N oticias (1979). Sobre la historia de este texto, ver Rojas, "Entrevista con Pedro Lastra”, 387-388. En su poema-posdata a la misma edición, Enrique Lihn afirma: "para decirlo todo en dos palabras/ sobre tu poesía: Pedro Lastra: / digo que ya eres parte de ella misma" (N oticias del extranjero. M éxico: Premiá, 1979. 99). Tanto "Una experiencia literaria en su contexto" como el poema de Lihn no aparecen en la última versión de $\mathrm{N}$ oticias. 
de origen variabley por tanto de identidad inestable: "¿quién habla aquí, quién está aquí?" (N oticias, 99). En este sentido, según Lilián U ribe, "la extranjería es ese designio, ese destino del que el poeta se enamora porque allí reside la fuerza dela insatisfacción que promueve un nuevo viaje [...]" ("M ester de extranjería”, 215). A partir de esta idea de U ribe es posible postular que aquello que la crítica Ilama "extranjería" no sólo es el destino del poeta sino que es la circunstancia que hace posible una poética como la de Lastra: la condición de extranjería permite proponer identidades textual es fragmentadas en constantemovimiento y una textualización radical de la experiencia. Dicha condición pone tierra de por medio entre el sujeto y el objeto en el sentido de distanciar tanto al hablante de su objeto del deseo (su propia identidad, la mujer amada, el hogar familiar, etc.) como al autor y su propia escritura. Pero a la vez acorta esa distancia al textualizar el mundo y, por tanto, cambiar la naturaleza del objeto: la experiencia del mundo es reemplazada por la del poema.

La transformación metódica de $\mathrm{N}$ oticias en sus sucesivas ediciones desfamiliariza el texto al convertir al autor en un "escrilector" y a este cuerpo de textos en un entramado inestable de referencias internas y externas pasadas y futuras $^{33}$. El viaje en esta poética es la reescritura como práctica y fenómeno $0^{34}$. En tanto práctica, se refiere a Pedro Lastra como lector, corrector y re-escritor de su propia obra. Como fenómeno, tieneque ver no sólo con un hablante que entra y sale de estados de conciencia, lugares físicos y recuerdos, sino también con la presencia de referencias a otras obras poéticas y a las versiones anteriores de ella misma. M i lectura ha enfatizado el aspecto fenoménico porque incluye muchas de las características de la reescritura como práctica. Se trata, entonces, de una poética que tiene como horizonte una imagen del poema como artefacto perfectible. M ediante la reescritura, se esmera en pulir atando los dos extremos temporales: mantiene la memoria y a la vez la va perfeccionando. Y la tensión utópica radica exactamente en la persistente y la sistemática revisión, aun cuando su producto genere una y otra vez imágenes fragmentarias, borrosas o inestables del mundo, de aquello que se desea o que se ha perdido y dela identidad propia. Esta poética propone la lectura y la escritura como la esencia del viaje, cuyo residuo es este conjunto de textos en permanente transformación que constituyeN oticiasdel extranjero. Esuna obra que podría caber dentro de lo queO ctavio Paz Ilama "poesía de convergencia", ya que combina cierta inestabilidad en el nivel del contenido con una voz poética que enuncia, corrige y reescribe metó-

\footnotetext{
${ }^{33}$ Sobre el "escrilector", ver Rojas, "Entrevista con Pedro Lastra", 387-388.

${ }^{34} \mathrm{O}$ 'H ara sostiene que el viaje insinúa un encuentro con la poesía misma (La precaución y la vigilancia, 21).
} 
dica y sistemáticamente ${ }^{35}$. Q ueda esperar entonces la próxima entrega de las $\mathrm{N}$ oticias de Pedro Lastra.

\section{BIBLIO GRAFIA}

Alonso, M aría N ieves. 1997. "Blues del extranjero. El último libro de Pedro Lastra". Acta literaria 22: 119-126.

Bloch, Ernst. 1959. D as Prinzip H offnung. Frankfurt am M ain: Suhrkamp. 3 tomos. - - - - . 1988. "Something's M issing: A D iscussion between Ernst Bloch and Theodor W. Adorno on the Contradictions of Utopian Longing". The U topian Function of Art and Literature. Selected Essays. Trad. J. Zipes \& F. M ecklenburg. Cambridge: M IT Press, 1-17.

Canfield, M artha. 2002. "Eternità dell'esilio: la poesia di Pedro Lastra". Q uaderni Ibero-Americani 92: 27-35.

Cioran, E.M . 1960. Histoire et utopie. París: Gallimard.

Cruz, Francisco José. s/f. "Lector de todas las horas. Entrevista a Pedro Lastra". M S. D omínguez V ial, Luis. 1995. "La poesía de Pedro Lastra". Atenea 471: 219-235.

Foxley, Carmen. 1983. "Intervención al margen". Acta Literaria 8: 99-101.

García M ontoro, Adrián. 1989. "El extranjero y el doble: La poesía de Pedro Lastra”. H ispamérica 53-54: 185-193.

Gomes, M iguel. 1992. "Sueños de paraíso y deluz. La poesía de Pedro Lastra". Revista chilena de literatura 40: 105-113.

Lastra, Pedro. 1980. Conversacionescon EnriqueLihn. 2ª ed. Santiago deC hile: Atelier, 1990.

- - - - . 1998. Noticias del extranjero (1959-1998). Santiago de Chile: Lom.

- - - - . 2002. "Poesía y exilio". Atenea 485: 103-114.

O 'H ara, Edgar. 1996. "La poesía es el pez en el agua: Conversación con Pedro Lastra”. Inti 43-44: 343-359.

----- . 1996. La precaución y la vigilancia. La poesía de Pedro Lastra. Valdivia: Barba de Palo,

Paz, O ctavio. 1990. La otra voz. Poesía y fin de siglo. Barcelona: Seix Barral.

Pellegrini, M arcelo. 1997. "El ejercicio memorioso de Pedro Lastra”. Revista de crítica literaria latinoamericana 23.45: 351-356.

Rivera, Francisco. 1994. "H acia una lectura de N oticias del extranjero". Revista iberoamericana 168-169: 835-839.

Rojas, M ario A. 1985. "Entrevista con Pedro Lastra". D iscurso literario 2.2: 379-394.

Sarup, M adan. 1994. "H ome and I dentity". Travellers' Tales. N arratives of $\mathrm{H}$ ome and D isplacement. G. Robertson et alia, eds. Londres: Routledge. 93-104.

${ }^{35} \mathrm{Al}$ referirse a los poetas de fin de siglo, Paz afirma quebuscan el principio invarianteque rige el cambio. También explica que esta poesía "es un perpetuo recomienzo y un continuo regreso [... ] busca la intersección de los tiempos, el punto de convergencia" (La otra voz, 5354). 
U ribe, Lilián. 1994. “M ester de extranjería: La poesía de Pedro Lastra”. Inti 39: 215218.

Zapata, M iquel Angel. 1988. “Pedro Lastra: La restricción de la palabra”. Inti 26-27: 197-205.

- - - _ - . 1994 . “M orada y memoria de Pedro Lastra”. Revista de Crítica Lite raria Latinoamericana 20.39: 295-300. 